\title{
Vibration control laws via shunted piezoelectric transducers: A review
}

\author{
Ehtesham Mustafa Qureshi*, Xing Shen** and JinJin Chen*** \\ College of Aerospace Engineering, State Key Laboratory of Mechanics and Control of Mechanical Structures, Nanjing University \\ of Aeronautics and Astronautics, No. 29 Yudao Street, Nanjing 210016, China.
}

\begin{abstract}
Attaching a piezoelectric transducer to a vibrating structure, and shunting it with an electric circuit, gives rise to different passive, semi-passive, and semi-active control techniques. This paper attempts to review the research related to structural vibration control, via passive, semi-passive, and semi-active control methods. First, the existing electromechanical modeling is reviewed, along with the modeling methods. These range from lumped parameters, to distributed parameters modeling of piezostructural systems shunted by electrical networks. Vibration control laws are then discussed, covering passive, semi-passive, and semi-active control techniques, which are classified according to whether external power is supplied to the piezoelectric transducers, or not. Emphasis is placed on recent articles covering semi-passive and semi-active control techniques, based upon switched shunt circuits. This review provides the necessary background material for researchers interested in the growing field of vibration damping and control, via shunted piezostructural systems.
\end{abstract}

Key words: Damping, Piezoelectric, Shunt, Switch

\section{Introduction}

The attenuation of vibration is desired in many engineering fields. Prominent among these are aerospace applications [1-5]. Due to technological advancements in the aerospace industry, there is an increased trend towards designing largescale and light-weight flexible structures, with the ability to carry man and material over long distances, at reduced cost. However, proper functioning of these flexible structures is usually associated with controlling vibrations at low frequency modes. The use of conventional vibration damping materials is limited, as they require more space and weight, and have an inability to control vibration at low frequency. Due to their small volume, lightweight, mechanical simplicity, and ease of integration with flexible structures, Piezoelectric (PZT) materials have emerged as the material of choice for vibration control purpose, among various researchers and engineers. These so-called smart materials exhibit excellent sensing and actuation abilities, along with a high electro-mechanical coupling coefficient. Piezoelectric materials work on the principle of piezoelectricity. When mechanically strained, piezoelectric material generates electric charge or voltage, which can be used for sensing purpose. This phenomenon is known as the direct piezoelectric effect. On the other hand, when an electric field is applied across the piezoelectric material, mechanical stress or strain is induced, which can be used for actuation purpose. This phenomenon is known as the converse piezoelectric effect.

Vibration control using piezoelectric transducers can be categorized into passive, active, semi-passive, or semi-active. The simplest among these are passive control systems using a piezoelectric patch, shunted by a resistive-inductive $R L$ electric network [6-12]; but variation in system parameters causes degradation in their control performance. Also, these systems require high shunt impedances for low frequency vibration attenuation. On the other hand, active control systems [13-15], are highly effective for low frequency vibration control; however, they require big power amplifiers and high performance digital signal processors to drive actuators, which is not feasible in most practical situations.
This is an Open Access article distributed under the terms of the Creative Commons Attribution Non-Commercial License (http://creativecommons.org/licenses/by$\mathrm{nc} / 3.0 /$ ) which permits unrestricted non-commercial use, distribution, and reproduction in any medium, provided the original work is properly cited. (c) * Ph. D Candidate
** Professor, Corresponding author: shenx@nuaa.edu.cn
*** Graduate Student 
Semi-passive and semi-active control systems have recently proved to be an attractive option for vibration attenuation, to overcome the disadvantages of passive and active control systems. Their advantages, compared to active control techniques, include more broadband frequency of operation over passive control, and less energy consumption.

Over the last two decades, different vibration control laws using piezoelectric materials have been extensively proposed, and have been used for diverse applications. This becomes clear from the following review articles: Sunar \& Rao [16] gave a comprehensive review of recent research activity related to the use of piezoelectricity, in the sensing and control of various flexible structures. The article comprised 336 references, which are classified according to their applications. Tang et al. [17] examined the past research efforts, and suggested future prospects regarding piezoelectric based semi-active and active-passive hybrid structural damping. Benjeddou [18] made the first attempt to survey and discuss advances in finite element modeling of smart structure during the last decade. Potential gaps were identified, and future directions were set. In the past, active (piezoelectric) and passive (viscoelastic) controls have also been combined, to form hybrid controls for structural vibration suppression. This unified approach provided broadband control, and benefited from the advantages of both active (high performance, adaptability), and passive (reliability, low cost, robustness) systems. Benjeddou [19] and Trindade \& Benjeddou [20] reviewed recent advances in geometric configurations, modeling approaches, and control algorithms of these hybrid active-passive damping treatments. Moheimani [21] presented an overview of vibration damping and control using shunted piezoelectric transducers, and investigated the similarities between shunt damping, and collocated active vibration controllers. He also demonstrated that shunted piezoelectric based vibration control problem can be viewed as a specific feedback control problem. Piezoelectric materials have also extensively been used in power harvesting techniques using ambient vibration energy. Sodano et al. [22] reviewed piezoelectric based energy harvesting using ambient mechanical vibration, and investigated power harvesting efficiency, discussing power storage and circuitry. In the years following the article by Sodano et al. [22], Anton and Sodano [23] reviewed research related to improving the efficiency of piezoelectric based energy harvesting through physical and geometric configurations, adaptive circuitry and energy removal techniques. In a recent article, Wang and Inman [24] discussed the possibility of using harvested energy through piezoelectric means, to provide power to control systems for suppressing vibrations. The use of piezoelectric materials has also extended to the vibration control of civil structures. Song et al. [25] reviewed structural control application of piezoelectric materials in beams, trusses, steel frames, and cable-stayed bridges. The advantages of piezoelectric materials were also discussed, along with the limitations, for actual implementation of these materials in civil structures. In a two-part article on the state-of-the-art, Fisco \& Adeli [26, 27] reviewed active, semi-active, and hybrid controls, using a variety of systems in civil structures, and discussed different control strategies.

This article presents a review of vibration control laws via shunted piezoelectric transducers, classified as passive control, semi-passive control, and semi-active control. First, the existing electromechanical modeling methods of piezostructural systems shunted by electrical networks are briefly reviewed, ranging from lumped to distributed parameter modeling. A comprehensive review is then initiated, covering different vibration control laws via shunted piezoelectric transducers, as reported in the literature over the last two decades. This places particular emphasis on recent articles, and covers semi-passive and semi-active shunt damping techniques with external power supply. At this stage, the authors would like to point out that there is a difference between semi-passive and semi-active control. Some researchers have used both "semi-active" and "semi-passive" control to represent different shunt damping circuits with external power supply e.g. Qiu et al. [80]. However, in this article, an electric shunt circuit will be taken as semi-passive, if and only if it does not provide power to the system - otherwise it will be considered as semi-active.

\section{Modeling of Shunted Piezostructural Sys- tems}

Both lumped parameter and distributed parameter modeling approaches have been utilized by different researchers to predict the electromechanical behavior of piezostructual systems shunted by electrical networks, for optimal damping and control performance. Larson \& Rogers [30] derived a lumped parameter model to predict the frequency changes between resonance states, for a state switched piezoelectric based acoustic transducer for underwater applications. Davis \& Lesieutre [29] developed a lumped parameter model of an electrically shunted passive vibration absorber, in which effective stiffness of the piezoelectric actuator was modified; this, in turn, changed the natural frequency of the device, in accordance with the variable frequency of the host structure. Mathematical expressions for the effective stiffness of piezoelectric 
elements were also developed. A simple lumped parameter model was developed by Badel et al. [31] for a semipassive shunt damping system; this was 100 times faster, compared to finite element simulations in ANSYS. Lumped parameter modeling for piezoelectric shunt damping was also effectively utilized by Corr \& Clark [28]; Cunefare [32]; Niederberger et al. [33]; and Lallart et al. [34], in their work.

Alternatively, Hagood et al. [7] utilized the distributed parameter model, using the generalized version of Hamilton's principle with Rayleigh-Ritz formulations, to derive equations of motion of an electroelastic continuum containing piezoelectric materials. The application of this generalized model was effectively used in a special case for a cantilevered piezostructure shunted by electrical networks. Euler-Bernoulli beam assumptions have been used by Guyomar et al. [35], and Ji et al. [36]; in particular, the assumptions were used by Ji et al. [37] to model the electromechanical behavior of cantilever piezostructure shunted by electrical elements. Erturk and Inman [38] identified several oversimplified and incorrect assumptions made in the literature relating to the electromechanical modeling of piezoelectric energy harvesters, from the use of low fidelity models, to incorrect base motion modeling, as well as the use of static expression in a fundamentally dynamic problem. Corrections were made for piezoelectric coupling, and improved distributed parameter modeling was derived as an alternative to single-degree-of-freedom lumped models, for more accurate model prediction of piezoelectric energy harvesters.

The dynamic modeling of cantilever shunted piezostructural systems using these two modeling approaches, as used in the literature, is briefly introduced below.

\subsection{Dynamic Modeling of Cantilever Shunted Piezo- structural Systems}

A comprehensive analytical model of the shunted piezostructural system is very important, not only for optimizing the system's mechanical to electrical energy conversion, but also for optimizing the system design parameters for improved performance. A number of approaches have been used in the literature to model the electromechanical behavior of the cantilever shunted piezostructual systems, in order to satisfy the diverse research needs. In order to achieve different design goals, provide reliable estimation of physical systems, and to satisfy various application needs, an analytical model should be as simple as possible, yet be sophisticated enough to capture various important phenomena.

\subsubsection{Discrete or Lumped Parameter Modeling}

The electromechanical behavior of a vibrating structure containing piezoelectric elements can be modeled as a spring-mass-damper system, as shown in Fig. 1 (a). In its simplest form, the structure can be modeled as a second order model, if it is driven under harmonic excitation around one of its resonance frequencies. Assuming linear elastic properties for the structure and the piezoelectric elements, differential equation (1) can be established,

$$
M \ddot{u}+C \dot{u}+K_{E} u=\sum F_{i}
$$

where, $M$ represents the equivalent rigid mass, $C$ is the mechanical losses coefficient, $K_{E}$ is the equivalent stiffness of the mechanical structure and piezoelectric elements in a short-circuited condition, $u$ is the rigid mass displacement, and $\sum F_{i}$ represent the sum of all other forces applied to the equivalent rigid mass, including forces applied by the piezoelectric elements.

Equations (2) and (3) describe the electromechanical coupling of piezoelectric elements bonded on the vibrating structure,

$$
\begin{aligned}
& F_{p}=-\alpha V \\
& I_{p}=\alpha \dot{u}-C_{o} \dot{V}
\end{aligned}
$$

where, $F_{p}$ is the electrically dependent part of the force applied by the piezoelectric elements on the structure, $\alpha$ is the force factor, $C_{o}$ is the blocked capacitance of piezoelectric

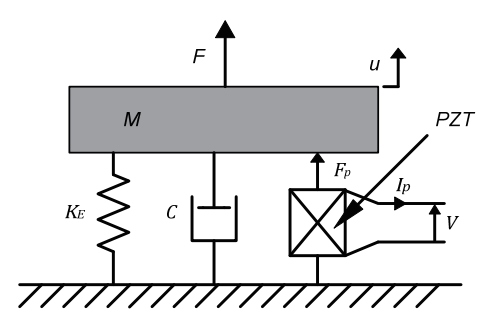

(a)

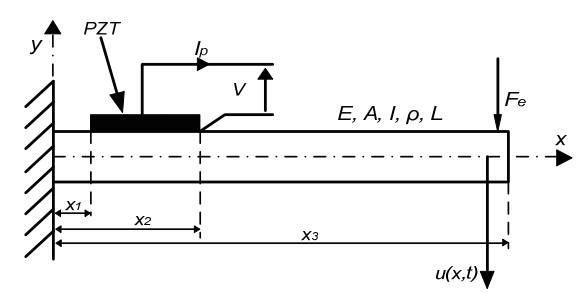

(b)

Fig. 1. Schematic representation of the (a) lumped parameter model, and (b) distributed parameter model, for piezoelectric shunt damping. 
elements, and $I_{p}$ is the outgoing current from piezoelectric elements. $M, K_{E}, \alpha$ and $C_{o}$ can be determined from the structural and piezoelectric elements characteristics, and the geometry. As $\sum F_{i}$ is the combination of $F_{p}$ and the external applied force on the structure i.e. the excitation force $F$, equation (1) can be written as

$$
M \ddot{u}+C \dot{u}+K_{E} u=F-\alpha V
$$

which represents the differential equation of motion of the electromechanical vibration system.

Multiplying both sides of equation (4) by velocity, and integrating over the time variable, gives the following energy equation (5)

$$
\int F \dot{u} d t=\frac{1}{2} M \dot{u}^{2}+\frac{1}{2} K_{E} u^{2}+\int C \dot{u}^{2} d t+\int \alpha V \dot{u} d t
$$

which represents the provided energy, in terms of kinetic energy, potential energy, mechanical losses, and transferred energy. Here, the transferred energy represents conversion of a part of the mechanical energy to electrical energy. By maximizing this energy, the mechanical energy, corresponding to the kinetic and potential energy in the structure, can be minimized. Due to its simplicity, this technique has been widely employed in the literature, such as in Guyomar et al. [39], and Badel et al. [31].

\subsubsection{Continuous or Distributed Parameter Modeling}

An alternative modeling approach is distributed parameter modeling, using the Euler-Bernoulli beam assumptions originally derived by Hagood et al. [7]. This has been used by other researchers, including Guyomar et al. [40] and Ji et al. [37], for the vibration analysis of a piezostructural system shunted by electrical elements. This modeling approach uses the Rayleigh-Ritz formulation to represent a discretized mechanical system, by reducing its mechanical degrees of freedom from an infinite dimension, to a finite dimension (Fig. 1 (b)). Neglecting the influence of the embedded piezoelectric patch on the stiffness, by assuming homogeneous material properties and uniform geometry of the vibrating structure, and denoting the deflection of the beam as $u(x, t)$, the equation of motion of a cantilever shunted piezostructural system, as shown in Fig. 1 (b), can be expressed as follows:

$$
\rho A \frac{\partial^{2} u(x, t)}{\partial t^{2}}+E I \frac{\partial^{4} u(x, t)}{\partial x^{4}}=f(x, t)
$$

where, $\rho(x)$ is the mass per unit length, $A$ is the crosssectional area, $E$ is the Young's modulus, $I$ is the moment of inertia, and $f(x, t)$ is the distributed external force. The force $f(x, t)$ is the combination of the force of excitation $f_{e}(x, t)$, and the control force generated by the piezoelectric actuator $f_{p}(x$, $t$ ). Modal analysis can be used to find the natural frequencies and modal functions.

The deflection of the beam under external excitation can be written as a finite series expansion of the modal function $\emptyset_{i}(x)$ and modal coordinate $u_{i}(t)$ for the ith mode by:

$$
u(x, t)=\sum_{i=1}^{\infty} \emptyset_{i}(x) u_{i}(t)
$$

Substituting (7) into (6), and considering the orthogonality of modal functions, the following equation can be obtained:

$$
M_{i} \ddot{u}_{i}+C_{i} \dot{u}_{i}+K_{E i} u_{i}=F_{e i}+F_{p i}
$$

where, $M_{i}$ is the modal mass, $C_{i}$ is the modal damping factor, $K_{E i}$ is the modal stiffness, $F_{e i}$ is the modal force of excitation, and $F_{p i}$ is the modal force generated by the piezoelectric transducer. In Equation (8), the term containing $C_{i}$ cannot be derived automatically from Equation (6); but it can be added artificially, to consider the mechanical damping. The system parameters in Equation (8) can be expressed as:

$$
\begin{aligned}
& M_{i}=\int_{0}^{L} \rho A \emptyset_{i}^{2}(x) d x, \\
& K_{i}=\int_{0}^{L} E I \emptyset^{\prime \prime 2}{ }_{i}^{2}(x) d x=\omega_{i}^{2} \int_{0}^{L} \rho A \emptyset_{i}^{2}(x) d x, \\
& F_{e i}=\int_{0}^{L} f_{e}(x, t) \emptyset_{i}(x) d x, \\
& F_{p i}=\int_{0}^{L} f_{p}(x, t) \emptyset_{i}(x) d x
\end{aligned}
$$

The damping coefficient $C_{i}$ must be estimated experimentally. Since $f_{p}(x, t)$ is proportional to the voltage on the piezoelectric patch, $F_{p i}$ can be expressed in the following form: $F_{p i}= \pm \alpha \mathrm{V}$, where the sign depends on the poling direction of the piezoelectric material, and $\alpha$ is the device coupling coefficient, which is the function of the size, location, elastic modulus, and other piezoelectric based properties of transducers, as well as the parameters of the baseline structure.

By considering the control of resonant vibrations at its first natural frequency, the vibrating structure can be simplified to a single degree-of-freedom. This allows one to obtain the following energy equation, by multiplying both sides of equation (8) by the velocity, and integrating over the time variable:

$$
\int F_{e} \dot{u} d t=\frac{1}{2} M \dot{u}^{2}+\frac{1}{2} K_{E} u^{2}+\int C \dot{u}^{2} d t+\int \alpha V \dot{u} d t
$$

In the above equation, the index has been omitted. Equation (9) is similar to equation (5), representing the external excitation energy in terms of kinetic energy, potential energy, mechanical losses and the transferred energy, with explanation similar to that given for equation 
(5). The solution predicted by the distributed parameter model tends to agree more precisely with the experimental result. However, due to its potential larger order, it tends to complicate the design and the control effort, as compared to the lumped parameter model.

The following section reviews the literature on the vibration control laws for shunted piezostructural systems, along the lines of passive, semi-passive, and semi-active control, with their classification based on whether external power is supplied to the piezoelectric transducers, or not.

\section{Control Laws for Shunted Piezostructural Systems}

\subsection{Passive Shunt Damping}

Shunting a piezoelectric transducer with an electrical circuit, and tuning it to dissipate mechanical vibrations of the host structure, constitutes a passive shunt damping. Mechanical strain energy is converted into electrical energy via the direct piezoelectric effect, which is dissipated through joule heating, by a passive electrical network. It is necessary to point out at this stage that the term "passive" is used by various researchers in different senses. For some, it represents autonomous shunt damping circuits, without external power supply. For others, e.g. Anderson \& Sumeth [81], an electric shunt circuit is said to be passive, if and only if it does not provide power to the system. In this review, the preceding cases will be considered as "passive control", and the succeeding ones as "semi-passive control". The basic configuration of three typical passive shunt damping circuits is shown in Fig. 2. As no external power or sensing element is needed for their operation, these systems are inherently stable. These vibration control and damping techniques have been used by many researchers in the past e.g. by Caruso [41], Hagood et al. [7], Hagood \& Crawley [8], Hollkamp [10], Hollkamp \& Starchville [42], Konak et al. [43], Richard et al. [44], Tang \& Wang [45], Thorp et al. [46], and Wu $\&$ Bicos [47]. It is worth mentioning here that these systems can be configured into resistance $(R)$, inductance $(L)$, and capacitance $(C)$, or a combination of these, as well as various series and parallel circuit combinations, for various shunt damping techniques.

The simplest of these configurations is resistive shunt damping, as shown in Fig. 2 (a), in which structural vibration is damped through the dissipation of mechanical energy into heat, as explained by Johnson [48].

Forward [6] is regarded as the pioneer in putting forward the idea of using piezoelectric transducers shunted by electrical networks to damp structural vibrations. He used an inductive $(L C)$ shunt, as shown in Fig. 2 (b), for narrow-band attenuation of resonant mechanical excitation. Vibration damping was achieved by canceling the inherent capacitive reactance of the piezoelectric transducer through the inductive shunt. Later, Hagood \& von Flotow [9] interpreted the $L C$ resonant circuit operation as analogous to that of a tuned mass damper. Moreover, they added a resistive element in the existing $L C$ shunt circuit, to make a $R L C$ tuned shunt circuit. By adopting an appropriate value of $R$, and choosing the value of $L$ according to the following equation (10), the vibration attenuation associated with a particular mode can be achieved.

$$
L=\frac{1}{\omega_{i}^{2} C_{p}}
$$

Here, $\omega_{i}$ is the angular resonant frequency of the $i t h$ mode of the vibrating structure, and $C_{p}$ is the capacitance of the piezoelectric transducer. Inspired by the work of Hagood \& von Flotow [9], other researchers also advanced research work that addressed a variety of similar problems. For instance, $\mathrm{Wu}$ [49] suggested that by replacing a series $R L$ shunt with a parallel one, similar vibration damping performance can be achieved, together with the performance being less sensitive to changes in resistive element. By using many shunt branches, the single mode shunt damping technique can also be applied for multimode suppression. For example, Hollkamp [10] suggested a resonant shunt circuit with many parallel $R L C$ shunt branches, with the very first branch as the $R L$ circuit, as shown in Fig. 3. Hollkamp's circuit behaves

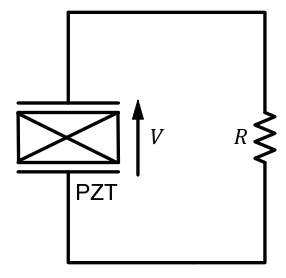

(a)

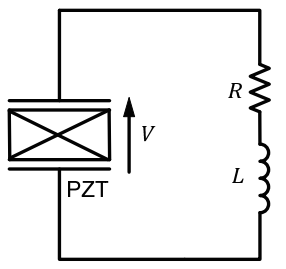

(b)

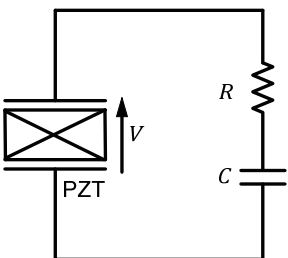

(c)

Fig. 2. Passive shunt damping system using PZT-based transducers: (a) resistive shunt, (b) inductive shunt, and (c) capacitive shunt. PZT: Piezoelectric material. 
similar to that of Hagood \& von Flotow's [9] circuit for single mode vibration control, while it can be extended to other modes, with the subsequent addition of parallel $R L C$ shunt branches, as per requirement. Similarly, dell'Isola et al. [50] distributed an array of piezoelectric transducers shunted with $R L$ circuits on the host beam, for multimode vibration suppression.

Fig. 2 (c) represents a capacitive shunt circuit, where the vibration absorber is tuned by changing the structural effectiveness. However, little research has addressed the passive capacitive shunt to date. Actively tuned capacitive shunts were investigated by Edberg \& Bicos [82], and Davis \& Lesieutre [29].

\subsection{Semi-Passive Shunt Damping and the Switch- ing Mechanism}

As no external power is supplied, passive shunt damping techniques exhibit a stable nature. But these techniques are not very practical and effective, especially in those cases

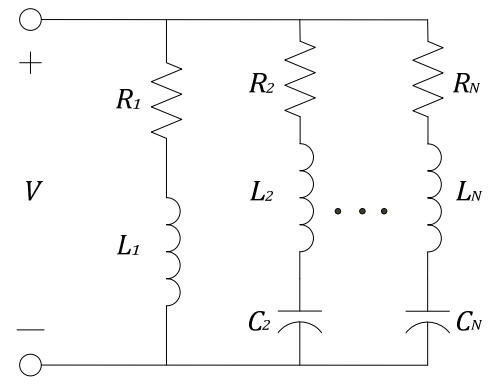

Fig. 3. Hollkamp circuit. where there is a requirement of large amplitude vibration attenuation, where broadband vibration control is required, where structural resonant frequencies are low, where the structural modeling is not completely known, or the system disturbance is unknown. Also, these techniques are sensitive to changes in system parameters due to environmental variation and loads, which cause degradation in their control performance. Therefore, to overcome the drawbacks associated with passive damping techniques, the so-called semi-passive and semi-active shunt damping techniques were developed. As mentioned earlier, in semi-passive control, the shunt circuitdoes not provide power to the system. Basically, vibration attenuation is achieved nonlinearly in these techniques, using an electronically operated switch, to adaptively tune the shunt parameters to match the resonance frequencies of the vibrating structure. Fig. 4 shows various switching techniques used in the literature, which are: (a) state switch: switching the shunt circuit from open circuit to short circuit; (b) synchronized switched damping (SSD) on a resistance (SSDS); (c) synchronized switched damping on an inductance (SSDI): as compared to the inductive shunt as shown in Fig. 2 (b), very small inductance in needed in this case; (d) synchronized switched damping on voltage source (SSDV); (e) synchronized switched damping on negative capacitance (SSDNC); and (f) synchronized switched damping on negative capacitance and inductance (SSDNCI). These semi-passive and semi-active control techniques are basically nonlinear techniques, due to the switching mechanism used for vibration control. Also, energy transfer between the electrical and mechanical domains is dealt with

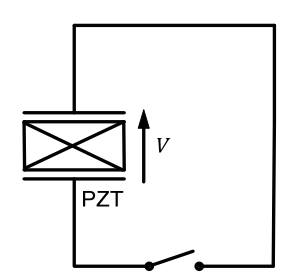

(a)

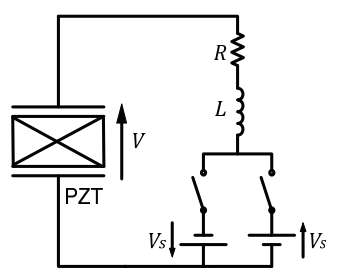

(d)

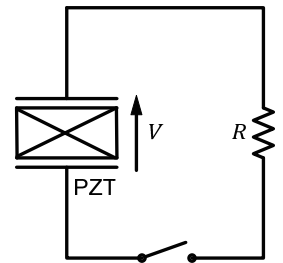

(b)

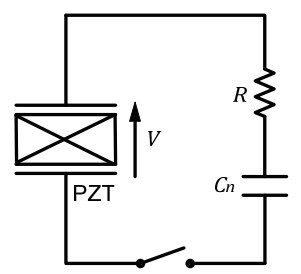

(e)

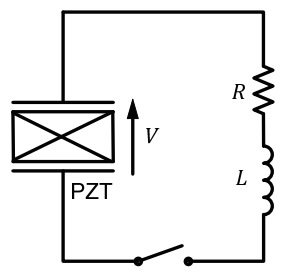

(c)

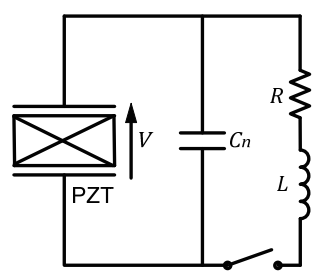

(f)

Fig. 4. Schematic diagram of (a) state switch, (b) SSDS, (c) SSDI, (d) SSDV, (e) SSDNC, and (f) SSDNCI.

PZT: piezoelectric material; SSDS: synchronized switched damping on resistance; SSDI: synchronized switched damping on inductance; SSDV: synchronized switched damping on voltage source; SSDNC: synchronized switched damping on negative capacitance; SSDNCI: synchronized switched damping on negative capacitance and inductance. 
in these techniques. The techniques are reviewed as follows:

\subsubsection{State Switching}

As shown in Fig. 4 (a), the state switching technique uses the concept of energy dissipation through piezoelectric materials, which have the ability to change their equivalent effective stiffness, according to the type of electrical connection (Ramaratnam \& Jalili [51]; Richard et al. [44]). More specifically, when the piezoelectric material is connected in an open circuit, it possesses a particular stiffness; and when it is short circuited, it possesses a different stiffness, in particular, a relatively low stiffness. When during excitation, the system moves away from equilibrium position, its potential energy increases, and is maximized at the maximum displacement point. At this point, the system is switched to low stiffness state, causing a lowering of potential energy; this, in turn, causes energy dissipation in the system. When the system starts moving towards the equilibrium position, the reduced potential energy is then converted into kinetic energy again. Thus, the overall energy available for the next half cycle is always lower than the previous cycle; and the whole process is repeated again, until vibration attenuation is achieved.

Larson \& Rogers [30] originally used the concept of state switching to develop a high-power, low frequency, broadband acoustic transducer for underwater applications. The stiffness, and consequently the natural frequency of the acoustic transducer, was changed, to match it with the changing frequency of the high amplitude signal. Later, Clark [52] used the same technique to dissipate energy from the vibrating system, by switching the shunted piezoelectrical network between high stiffness (open-circuit) and low stiffness (short or resistive-circuit) states. The actuator stores the system's energy during movement, and is held in a high stiffness state. The stored energy is then dissipated, by switching the actuator to a low stiffness state, just before the system is ready to receive the stored energy back from the actuator. Numerical simulations conducted for a cantilever beam showed that the vibration suppression is dependent on the effective stiffness change. Clark [53] extended this approach to numerically study three different piezoelectric shunt circuit configurations, i.e. a passive resistive shunt, state-switched open-to-short-circuit, and state-switched open-to-resistive circuit. Note that he used "state switch" to represent not only open-to-short-circuit switching (Fig. 4 (a)), but also open-to-resistive switching. However, for convenience, "state switch" is denoted in this paper by switching from open to short circuit, as shown in Fig. 4 (a); and "SSDS" is denoted by synchronized switching on resistive shunt (Fig. 4 (b)). Simulations were performed for both the impulse response and harmonic response cases. It was found that for the impulse response, as compared to the state switch and SSDS, damping performance of the passive resistive shunt (Fig. 2 (a)) was slightly better for the optimized cases; but the performance deteriorated significantly, when the resistors were no longer optimized. For the harmonic response, passive resistive shunt systems performed well in the high frequency range, and near resonance; while state switch and SSDS performed well in the low frequency region, where stiffness is a more dominant factor in the response. Therefore, it was concluded that the state switch and SSDS outperformed passive resistive shunt systems, and could be an alternate to active vibration control systems, in certain frequency ranges. The idea was extended to the case in which additional stiffness was added to the system, in the form of the piezoelectric patch and cantilever beam. Effective stiffness change up to a factor of 2 and 1.8 was observed, when the piezoelectric transducer was operated in $d_{33}$ and $d_{31}$ modes, respectively, for the layered beam. Increasing the piezoelectric coupling coefficient increases the stiffness change of the system. Clark used the term "adaptive passive" or "semi-active" to represent this state switching technique [53]; but we classified this technique as semi-passive, since external power is supplied only for the switch to operate, and is not for the system.

Corr \& Clark [28] compared the performance of passive resonant shunt technique with state switching and SSDI techniques, both numerically and experimentally. They derived the optimal shut time period for the SSDI technique as

$$
\Delta T_{\text {shut }} \cong \pi \sqrt{L C_{o}}
$$

where, $\Delta T_{\text {shut }}$ is the shut switch time period, $L$ is the inductance of the shunt circuit, and $C_{o}$ is the capacitance

Table 1. Numerical and experimental shunt circuit parameters, in Corr \& Clark [28].

\begin{tabular}{lccc}
\hline & $\begin{array}{c}\text { Resonant } \\
\text { Shunt }\end{array}$ & State Switching & SSDI \\
\hline Resistance_Numerical $(\Omega)$ & 2900 & $1 \mathrm{E}-06$ & 70 \\
Inductance_Numerical $(\mathrm{H})$ & 287 & 0 & 0.10 \\
Resistance_Experimental $(\Omega)$ & 815 & 0.008 & 66 \\
Inductance_Experimental $(\mathrm{H})$ & 10.5 & 0 & 0.50 \\
\hline
\end{tabular}


of the piezoelectric transducer. From the numerical and experimental results, as shown in Table 1, it was concluded that both the resonant shunt and SSDI techniques performed better that the state switching technique. It was hard to tell whether SSDI would always perform better than the resonant shunt. However, the use of the $0.1 \mathrm{H}$ inductor in SSDI, as compared to the $287 \mathrm{H}$ inductor used in the resonant shunt technique, made SSDI more suitable for practical applications.

The experimental comparison for each method was conducted for the third vibration mode of a clampedclamped beam, as shown in Table 1. The optimal resistance and inductance for the resonant shunt was first calculated using the relations given by Hagood \& von Flotow [9]. They were then tuned to yield the smallest structural response at the third mode. Experimental results showed that the state switching technique did not perform well ( $\sim 2 \mathrm{~dB}$ reduction). The SSDI, however, did just as well as the resonant shunt technique ( $\sim 12 \mathrm{~dB}$ reduction), but with a much smaller shunt inductance ( 20 times smaller). The SSDI was also easier to tune, and was less susceptible to system changes, than the resonant shunt technique. Note that an upper bound for the inductance was set, to ensure that the electrical natural frequency was at least ten times faster than the vibration mode of interest. A lower bound for the inductance was introduced and set in Corr \& Clark [54], in order to avoid the chatter effect.

Cunefare [32] applied the technique of state switching for the purpose of vibration control of beams subjected to harmonic point-force excitation. A switchable stiffness was integrated with the spring element for a vibration absorber, which caused instantaneous "retuning" of the state-switched absorber to a new frequency. Holdhusen \& Cunefare [55] compared this state switched absorber with the classical vibration absorber, in terms of damping effect, and concluded that highest relative performance of the state switched absorber, as compared to the classical vibration absorber, occurred at low values of damping. Corr \& Clark [56] expanded the SSDI technique for multimode vibration control, based on the rate of change of energy in controlled modes. The technique was numerically and experimentally tested on a six degree-of-freedom spring-mass system, and a clamped-clamped aluminum beam, respectively. Simulation and experimental results showed that this technique was able to dissipate energy in multimodes, both simultaneously and selectively. Experimental results also showed that for a beam under a constant random disturbance, the vibration attenuation achieved was $11 \mathrm{~dB}$ for a single mode, and $7 \mathrm{~dB}$ for multiple modes.

\subsubsection{Synchronized Switched Damping on Resistance (SSDS)}

Richard et al. [83, 44] originally introduced the concept of SSD, by switching the resistive shunt from open to short circuit, in synchronicity with the structural motion (Fig. 5 (a)). SSD on resistive shunt will be called SSDS, to distinguish it from other SSD techniques e.g. SSDI, SSDV etc. In this SSDS technique, the voltage on the piezoelectric element attached to the vibrating structure, which is the image of the structure's displacement, is switched to zero, when the displacement reaches a predetermined threshold. The switching action was performed through a pair of $\mathrm{N}$-Channel MOSFET transistors $T_{1}$ and $T_{2}$, and a pair of fast recovery diodes $D_{1}$ and $D_{2}$, wired as in Fig. 5, where, $V_{g s}$ is the transistors drive signal. As a consequence of this switching, the resulting voltage on the piezoelectric element is distorted and time-shifted from the structural displacement, thus creating a kind of controlled viscous damping. Using a basic spring mass model, the distorted and time-shifted piezoelectric output voltage $V(t)$ was modeled as,

$$
V(t)=j \alpha \beta \operatorname{Cos}(\varphi) u(t)
$$

where, $\mathrm{j}=\sqrt{ }(-1), \alpha$ is the electromechanical coupling coefficient of piezoelectric transducer, $\beta$ is the harmonic amplitude, $\varphi$ is the phase angle between the mass velocity and the chopped voltage, and $u(t)$ is the structural displacement. Thus, improvement in damping can be achieved by increasing the factor $\alpha \beta \operatorname{Cos}(\varphi)$, which corresponds to decreasing the

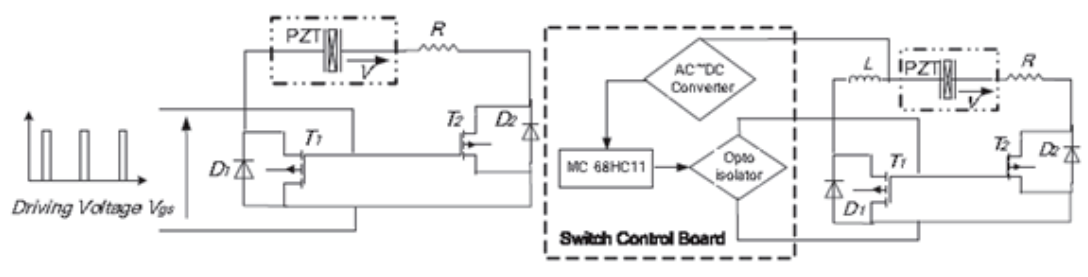

(a)

(b)

Fig. 5. The use of switching for (a) SSDS, in Richard et al. [44], and (b) SSDI, in Richard et al. [57]. PZT: piezoelectric material. 
phase angle $\varphi$, increasing the harmonic amplitude $\beta$, or increasing the electromechanical coupling coefficient of the piezoelectric transducer, e.g. using piezoelectric elements in the 3,3 longitudinal mode, instead of the 1,3 lateral one. Experiments were performed for both the harmonic and transient excitations. It was revealed that the shortest shunt time interval results in the most efficient damping. In the SSDS harmonic excitation experiment, a $20 \%$ decrease in the maximum amplitude of first mode at $10.5 \mathrm{~Hz}$ resonance frequency was achieved for a $54 \mathrm{k} \Omega$ resistor; while twice the damping was achieved, as compared to the adapted resistive shunt. In the SSDS transient experiment, a 30\% faster settling time was achieved, as compared to the open circuit one; while this time is only $18 \%$ faster in the case of the adapted resistive shunt circuit, in comparison with the open circuit.

\subsubsection{Synchronized Switched Damping on Inductance (SSDI)}

Later, Richard et al. [57] extended the SSD technique to include an inductance in the shunt circuit connected to the piezoelectric transducer, which is known as the SSDI technique (Fig. 5 (b)). Connecting an inductance in the shunt circuit results in an oscillating network. If properly designed and tuned, this allows the inversion of voltage on the piezoelectric electrodes. In this case, the voltage is optimized, and being 90 degree out of phase with the structure motion, enhances the damping mechanism. A simple microcontroller was used to generate a controlled width pulse, to drive a pair of NMOS transistors in synchronicity with the structure motion (Fig. 5 (b)). Using a simple spring-mass system, the electric charge $Q(t)$ appearing on the piezoelectric electrodes was modeled as,

$$
Q(t)=C_{o} V(t)+\alpha u(t)
$$

where, $C_{o}$ is the piezoelectric capacitance, $V(t)$ is the piezoelectric output voltage, $\alpha$ is the electromechanical coupling coefficient of the piezoelectric transducer, and $u(t)$ is the structural displacement. Harmonic and transient experiments were performed for three different cantilever beams, and the maximum damping performance of passive adapted resistive, SSDS, and SSDI techniques were compared. The results showed far better damping performance of SSDI, as compared to the other two techniques, for all beams; with a maximum damping of $6 \mathrm{~dB}$ for an epoxy beam, to $16.5 \mathrm{~dB}$ for a steel beam, using the SSDI technique. Table 2 gives global results for the three beams, in terms of resonant frequency, electromechanical coupling coefficient, transducer capacitance, critical damping resistance, maximum damping, and time constant.

Ducarne et al. [58] compared the control performance of SSDS and SSDI for both free and forced response. Some theoretical results are summarized in Table 3. Here, the added damping $\zeta_{\text {add }}$ is dependent only on the modal coupling coefficient $k_{r}$. An added damping of $2.5 \%$ with SSDS, and $10 \%$ with SSDI, is obtained for a structure with coupling coefficient $k_{r}=0.2$, and structural damping factor $\zeta_{r}$ $=0.1 \%$. The influence of the system parameters on the system response was also analyzed by the authors. This led to the following general conclusion: that the coupling factor is the only free parameter that has an influence on the performance of the SSD devices; and it has to be maximized, for enhanced

Table 2. Experimental parameters and damping results for SSDI, in Richard et al. [57].

\begin{tabular}{|c|c|c|c|}
\hline Reference name (material) & $\begin{array}{l}\text { Beam } 1 \\
\text { (epoxy) }\end{array}$ & $\begin{array}{c}\text { Beam } 2 \\
\text { (aluminum) }\end{array}$ & $\begin{array}{c}\text { Beam } 3 \\
\text { (steel) }\end{array}$ \\
\hline Short-circuit frequency $(\mathrm{Hz})$ & 10.33 & 13.09 & 12.75 \\
\hline Open-circuit frequency $(\mathrm{Hz})$ & 10.38 & 13.17 & 12.89 \\
\hline Coupling coefficient & 0.103 & 0.11 & 0.148 \\
\hline Capacitance $C_{o}(\mathrm{nF})$ & 280 & 190 & 90 \\
\hline Adapted shunt resistor $(\mathrm{k} \Omega)$ & 54 & 61 & 139 \\
\hline Maximum damping $(\mathrm{dB})$ - adapted resistive & -0.5 & -2 & -6 \\
\hline Maximum damping (dB) - switch on short circuit & -1.3 & -3.7 & -8.4 \\
\hline Maximum damping $(\mathrm{dB})$ - switch on an inductor & -6 & -10.5 & -16.5 \\
\hline Time constant (s) - open circuit & 0.8 & 1.5 & 6.5 \\
\hline Time constant (s) - switch on short circuit & 0.6 & 0.7 & 1.3 \\
\hline Time constant (s) - switch on an inductor & 0.4 & 0.3 & 0.5 \\
\hline
\end{tabular}

Table 3. Summary of the main characteristics of SSDS and SSDI systems in free and forced response, in Ducarne et al. [58].

\begin{tabular}{ccc}
\hline & Free response & Forced response \\
\hline SSDS & $\zeta_{\text {add }}=-\frac{1}{\pi} \ln \left(\frac{1-k_{r}^{2}}{1+k_{r}^{2}}\right)=2.5 \%$ & $A_{p}=f\left(k_{r}, \zeta_{r}\right)=30 d B$ \\
SSDI & $\zeta_{\text {add }}=-\frac{1}{\pi} \ln \left(\frac{1-\left|k_{r}\right|}{1+\left|k_{r}\right|}\right)=10 \%$ & $A_{p}=f\left(k_{r}, \zeta_{r}\right)=46 d B$ \\
\hline
\end{tabular}


vibration suppression. Therefore, it is possible to optimize every electrical parameter of the circuit against any value of coupling factor $k_{r}$, for enhanced damping performance. To evaluate the control performance of forced response, a performance index $A_{p}$ of amplitude attenuation is defined as,

$$
A_{p}=20 \lg \left(\frac{\text { closed loop vibration amplitude }}{\text { open loop vibration amplitdue }}\right)
$$

\subsection{Semi-Active Damping}

As mentioned earlier in this article, different researchers in the literature have used both the terms "semi-passive" and "semi-active" control, to represent various shunt damping circuits with external power supply. In this review, an electric shunt circuit is said to be semi-passive, if and only if it does not provide power to the system; otherwise, it is classified as semi-active. Based upon this classification, various semiactive damping techniques are reviewed, as follows.

Using only a single piezoelectric patch, Fleming \& Moheimani [79] developed an online adaptive shunt damping circuit for multimode vibration control. They provided the desired terminal impedance of an arbitrary shunt network, through a voltage-controlled current source and digital signal processor (DSP) system. Their experimental testing showed reliable estimation of the performance functions, and optimal tuning of the circuit parameters for a randomly excited simply supported beam. In addition, a reduction in magnitude of up to 22 and $19 \mathrm{~dB}$ for the second and third modes of this beam was achieved.

\subsubsection{Synchronized Switched Damping on Voltage Source (SSDV)}

The output voltage of the piezoelectric transducer can be further increased, by adding a voltage source $V_{s w}$ in the shunt circuit of SSDI, giving rise to SSDV technique, as shown in Fig. 4 (d), thus improving the damping performance. This concept was introduced and investigated by Petit et al. [59], in comparison with SSDS and SSDI techniques, both theoretically and experimentally. The damping coefficient was derived as a function of the system electromechanical coupling coefficient. It was shown that for SSDS and SSDI techniques, the damping performance is strongly correlated with the electromechanical coupling coefficient. But for the case of weakly coupled structures, SSDV can compensate for the drawback, by artificially increasing the voltage on the piezoelectric transducer, thus improving the damping. The switches were driven by a controller, which could detect the minimum and maximum voltage $V$. Experiments were performed on a cantilever beam, which verified the theoretical derivations. The SSDI technique was applied for bimodal vibration attenuation of a steel cantilever beam. The modes' relative amplitudes were used as an index to evaluate the damping performance, which showed approximately 10 $\mathrm{dB}$ of damping for both modes simultaneously. Finally, a clamped steel plate under broadband excitation was also tested, by using an SSDI technique. Experimental results showed that significant vibration reduction (between 2 to $9 \mathrm{~dB}$ ) for various modes was achieved, for frequencies lying between $180 \mathrm{~Hz}$ and $280 \mathrm{~Hz}$.

In the conventional SSDI technique, the voltage is inversed at each displacement extremum, which is optimal for single mode vibration attenuation; but for the case of multimode excitation, this may not be true. To address this issue, Guyomar \& Badel [60] developed an efficient probabilistic SSDI multimode vibration reduction technique, by allowing the piezoelectric voltage to reach a statistically probable value, before processing the voltage inversion. This technique simultaneously optimized both the displacement based and energy based vibration damping; this was unlike the control law based on mode selection method, as used by Corr \& Clark [56], which could not simultaneously optimize the displacement and the energy based vibration damping. The probabilistic control law, unlike the control law by modes selection, does not require any filtering devices for modes selection, or any information related to the structural modes; and therefore no time shift occurs between strain and the filtered voltage, resulting in an efficient switching sequence, and consequently, efficient damping performance. The optimized displacement and energy damping for the probabilistic approach were -8.5 and $-6.3 \mathrm{~dB}$, in comparison to -3.0 and $-4.3 \mathrm{~dB}$, respectively, when switched on all voltage extrema.

Lefeuvre et al. [61] added two voltage sources in the SSDV technique shown in Fig. 4 (d), to enhance the damping performance of the previous SSD techniques. Theoretical and Experimental results on a steel cantilever beam demonstrated a $83 \%$ reduction in piezoelectric material volume for the same vibration attenuation of $-24 \mathrm{~dB}$, by adding two voltage sources of $10 \mathrm{~V}$ each, in the switching circuit. Badel et al. [62] and Lallart et al. [63] found out that if the control force induced by the piezoelectric transducer is larger than the excitation force, the SSDV system becomes unstable. To avoid this instability, they proposed an enhanced SSDV $\left(S_{S D V}\right.$ enh $)$ technique, by using an adaptive continuous voltage source, instead of a constant continuous voltage source, as used in the classical SSDV technique. This permits the piezoelectric control force to match the force of excitations. Guyomar et al. [39] implemented an SSDV with single voltage source, to control the resonance frequency of 
the oscillating system, by controlling the structural stiffness. This technique relied on connecting the piezoelement to the electrical network, when the displacement or the strain crosses the zero value; unlike the classical SSDV technique, in which the switching occurs at the voltage extreme. Theoretical results were validated through the experiment, allowing the stiffness to be controlled within a wide range of value.

Guyomar et al. [64] proposed an enhanced SSDI technique, by analyzing the voltage or displacement signal in a give time window, and statistically determining the probable voltage or displacement level threshold from both the average, and the standard deviation, of the signal during the observed period. This allowed voltage switching only above the defined threshold, thus avoiding unnecessary switching at every instant, and thus improving damping performance. It was shown that the relevant switching instants could be more accurately identified by either a probability or a statistical analysis of the strain signal. Numerical methods could easily be used for the calculation of the average or rms value of a given signal. Also, for the best damping results, either the image of the strain i.e. the displacement, or its square, could be used. In this way, approximately $10 \mathrm{~dB}$ of global displacement could be achieved - nearly twice the value obtained from the classical SSDI technique.

In the classical SSDI techniques, the piezoelement is switched on the resonant electrical network at each detected extremum, resulting in the artificial increase of the electromechanical coupling coefficient. However, as discussed by Guyomar \& Badel [60], switching on each extremum is not the optimal solution for damping; it results in decreasing the damping in the lower vibration modes, which are often more energetic and better coupled than the higher modes. To address this issue, Lallart et al. [65] developed an adaptive SSDI technique, in which switching occurs only after a threshold value (matched on the voltage) is reached. The adaptive SSDI technique resulted in the vibration damping of more than $10 \%$ of the first and second modes, as compared to the classical SSDI technique.

Guyomar et al. [40] carried out an experimental study using SSDI technique, to analyze the effect of variations of excitation force amplitude and frequency on the damping performance of piezoelectric transducers. The vibration damping sensitivity w.r.t. the size of piezoelectric transducers in the lower and higher values of the above parameters was also studied. The switching sequence was implemented based on statistical analysis of the voltage or displacement signal. This statistical technique is easier to implement for any type of excitation force, and handles the trigger of an extremum in a better way. The experiments were carried out using two configurations of piezoelectric transducers, mounted on a cantilever beam. Each configuration consisted of a total of 12 and 24 transducers mounted equally on opposite sides of the beam. It was observed that the piezoelectric transducers with larger surface size gave better damping performance for low excitation frequencies, and that transducers with less surface size gave better damping attenuation for high excitation frequencies. Also, increasing the force amplitude increases the damping performance of piezoelectric transducers, but is limited by the size of piezoelectric surface area.

Neubauer \& Wallaschek [66] studied SSDI and enhanced SSDV techniques, both analytically and experimentally, to determine the optimal switching sequence and optimal frequency ratio between the electrical resonance and mechanical excitation. It was shown that the enhanced SSDV technique performed similar to the SSDI technique, but with an increased force factor for the piezoelectric element. Harari et al. [67] improved the classical SSDI semi-active control technique for broadband vibration attenuation, by using a modal observer, similar to that used in active control techniques. The observer required identification of the structure's modal characteristics, but nevertheless showed good robustness. The combination of the semi-active and active techniques required low power for its operation,

Table 4. Comparison of the 3 methods: Modal active control, semi-active control, and semiactive-modal control, in Harari et al. [67].

\begin{tabular}{llccc}
\hline & Modal active & $\begin{array}{c}\text { Semi-active } \\
\text { control }\end{array}$ & $\begin{array}{c}\text { Proposed control: } \\
\text { semi-active } \\
\text { modal control }\end{array}$ \\
\hline Performance & $\begin{array}{l}\text { Monomode resonance } \\
\text { control }\end{array}$ & Very good & Good & Good \\
& Wide bandwidth excitation & Very good & Poor & Good \\
& Modes targeting ability & Very good & Poor & Good \\
& Type of control & Global & Local & Global \\
& Modal model & Yes & No & Yes \\
Rorgy & Actuation energy & High & Null & Null \\
& Control processing energy & High & Low & High \\
& Stability robustness & Poor & Very good & Very good \\
& Performance robustness & Poor & Very good & Good \\
\hline
\end{tabular}


and no amplifiers were required to drive the actuators. The authors compared the modal active control, semi-active SSDI, and hybrid SSDI-modal control techniques, as shown in Table 4.

Lallart et al. [34] presented a new semi-active vibration control technique, called blind switch damping (BSD), in which the piezoelectric element was switched on a short circuit, or the magnitude of piezovoltage was artificially increased, by switching on piecewise constant, or adaptive, voltage sources. BSD technique allowed the control of reinjected harmonics, requiring lower power for the system to operate, as compared to the conventional SSD techniques. On the other hand, BSD showed low damping effect for equivalent parameters, as compared to the SSD methods.

The control performance of SSDV technique is strongly dependent on the value of the voltage source in the shunting circuit. Ji et al. [36] improved the previous SSDV techniques, by adaptively adjusting the voltage coefficient that controls the damping effectiveness. An improved switch control algorithm was developed that prevented the switch from over-frequent switching, thus ensuring system stability. The switch remains in an inactive state for a certain time period, and prevents any switching action, even when the extrema are detected; unlike the previous SSDV techniques, which caused switching at each detected extremum, thus causing system instability, and reduced damping performance. Ji et al. [68] applied the adaptive SSDV technique for the vibration control of a composite beam, using the least mean square (LMS) algorithm to adjust the voltage source. The LMS algorithm was applied to the classical SSDV method, to directly adjust the voltage; and to the enhanced SSDV method, to adaptively adjust the voltage coefficient. It was found that the LMS-classical SSDV needed less energy, than the LMS-enhanced SSDV method. Therefore, it is more efficient to directly adjust the voltage, than to adjust the voltage coefficient. The control results for the first vibration mode of the beam indicated that directly adjusting the voltage source, and adaptive adjustment of the voltage coefficient, resulted in almost the same vibration damping, with the LMS-based method showing better results than the derivative-based method. Ji et al. [69] developed an improved SSDI technique, based on a displacement threshold switch for multimode vibration control. The new switching algorithm prevented the switch from over-frequent switching, thus increasing the converted energy, and improving the damping performance. The switching algorithm was applied to control the two vibration modes of a composite beam. The experimental results showed that the proposed method improved the damping of the first mode from $3.7 \mathrm{~dB}$ to $18.2 \mathrm{~dB}$, as compared to the classical SSDI technique; while the damping performance dropped to $2.6 \mathrm{~dB}$ from $3.46 \mathrm{~dB}$ for the second mode, when the two modes were excited simultaneously. Ji et al. [37] presented an improved version of both the classical SSDI and SSDV techniques, based on an energy threshold, to control multimode vibration excitation. The new switching control strategy was based on setting a threshold on the displacement increments between two neighboring switching points to suppress the voltage inversion on some of the displacement extrema. That is, voltage inversion take place only on those extrema whose distance from the neighboring extrema are larger than a defined threshold; thus increasing the total converted energy, and improving damping. The improved SSDI using the new control strategy exhibited better damping performance than the classical SSDI techniques, especially for the first vibration mode. Meanwhile, the improved SSDV, using an adaptive voltage source in combination with the new control strategy, also gave much better control performance than the classical SSDV techniques. Experimental results showed much better control performance for the first mode in the two-mode control, than in the single-mode control.

Ji et al. [70] developed a self-sensing SSDI technique, by using a single piezoelectric element as both a sensor and actuator, thus reducing the total number of required piezoelectric elements. The noise generated in the sensor signal due to the impact of voltage inversions caused extra switching, and therefore deteriorated the damping performance. This issue was effectively addressed by developing a simple switch control algorithm that prevented over-frequent switching, resulting in improved damping performance, as compared to the classical SSDI technique. Ji et al. [71] theoretically and numerically studied the influence of switching phase delay and switching frequency on the converted energy in a piezoelectric actuator, using the switched voltage control system. Theoretical and numerical results on a 2-DOF model using an SSDI technique showed that the control performance deteriorated with increasing phase delay, and the force generated by the switched voltage becomes a force of excitation, when the phase exceeds $\pi / 2$. The result also showed that the control effect can only be achieved at some specific frequencies, which could be an important factor for multimode vibration control, meaning that damping on a particular mode cannot be achieved, if the voltage is switched on another mode. Statistical analysis showed that random switching of piezoelectric voltage does not produce any damping. Improved damping performance for real systems could be obtained, by suppressing the switching action induced by sensor noise. Ji et al. [72] presented a theoretical and numerical analysis of the energy conversion of SSDI and SSDV switch-voltage 
control techniques with arbitrary switching frequencies. A general expression was derived for the switched voltage on the piezoelectric actuator. Performance of both the SSDI and SSDV techniques with arbitrary switching frequencies were analyzed, and expressed in the form of a performance index in decibel, defined as,

$$
\begin{gathered}
\text { SSDI: } A_{p}=\left\{\begin{array}{c}
20 \log _{10}\left(1+K_{s} Q_{m} \frac{2}{\bar{\omega}} \frac{\left(1-\gamma^{2}\right)(\sin \bar{\omega} / 2)^{2}}{\left(\gamma^{2}+2 \gamma \cos \bar{\omega}+1\right)}\right) \\
\text { for } \bar{\omega} \neq(2 i-1) \pi \\
20 \log _{10}\left(1+K_{s} Q_{m} \frac{4}{(2 i-1) \pi} \frac{1+\gamma}{1-\gamma}\right) \\
\text { for } \bar{\omega}=(2 i-1) \pi
\end{array}\right. \\
\text { SSDV: } A_{p}=\left\{\begin{array}{c}
20 \log _{10}\left(1+K_{s} Q_{m} \frac{2}{\bar{\omega}} \frac{\left(1-\gamma^{2}\right)(\sin \bar{\omega} / 2)^{2}}{\left(\gamma^{2}+2 \gamma \cos \bar{\omega}+1\right)}\right) \\
\text { for } \bar{\omega} \neq(2 i-1) \pi \\
20 \log _{10}\left(1+(1+\beta) K_{s} Q_{m} \frac{4}{(2 i-1) \pi} \frac{1+\gamma}{1-\gamma}\right) \\
\text { for } \bar{\omega}=(2 i-1) \pi
\end{array}\right.
\end{gathered}
$$

where, $K_{s}$ is the structural coupling coefficient, $Q_{m}$ is the mechanical quality factor, $\gamma$ represents the voltage inversion efficiency, $\bar{\omega}$ is the switching period, $i=1,2, \ldots$ and $\beta$ is the voltage coefficient. A large value of performance index corresponds to higher control performance. The result indicated that the voltage magnitude on the piezoelectric actuator is maximized, when the piezoelectric is switched at every odd number of displacement extrema. The average converted energy per vibration cycle was also derived for an arbitrary switching frequency. The result indicated that energy conversion is maximized, when the voltage is converted at every displacement extrema. A slight deviation of switching frequency from the optimal frequency drastically reduced the energy conversion efficiency.

\subsubsection{Synchronized Switched Damping on Negative Ca- pacitance (SSDNC)}

Ji et al. [73] proposed a new SSD technique, called SSDNC (synchronized switch damping on negative capacitance)

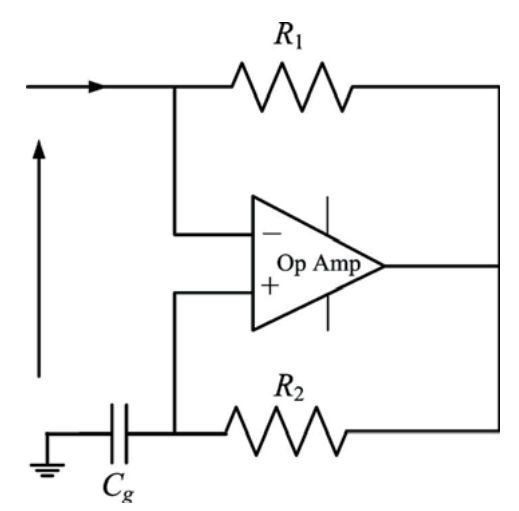

Fig. 6. The circuit of a ground negative capacitance, in Ji et al. [73]. (see Fig. 4 (e)). This uses a negative capacitance in the shunt circuit, instead of an inductance, as used in the traditional SSDI technique. The negative capacitance makes the whole circuit capacitive, without resonance; however, voltage inversion on the piezoelectric element is still possible. The magnitude of the piezoelectric element voltage is dependent on the ratio of the inherent capacitance of the piezoelectric element and the negative capacitance. By choosing an appropriate value of the negative capacitance, a large magnitude of voltage on the piezoelectric element can be obtained, thus ensuring good damping performance. As shown in Fig. 6, the negative capacitance can only be realized by a synthetic circuit. The input impedance of the circuit is

$$
Z_{\text {in }}=-\frac{1}{s R_{2} C_{g} / R_{1}}=-\frac{1}{s C_{n}}
$$

Hence, the circuit functions as a negative capacitance $-C_{n}=-\left(R_{2} C_{g}\right) R_{1}$. The value of negative capacitance can be changed, by changing the value of $R_{1}, R_{2}$ or $C_{g}$. The SSDNC technique was compared with the classical SSDI technique for the single-mode and two-mode vibration control of a composite beam. Experimental results demonstrated the effectiveness of the SSDNC technique over classical SSDI technique, especially in the single-mode control of the first resonance mode. In a similar treatment, Cheng et al. [74] demonstrated the effectiveness of the SSDNC technique, in comparison with the SSDI and negative capacitance passive shunt. In a work similar to Ji et al. [72], Ji et al. [75] used an SSDNC technique with an arbitrary switching frequency for the vibration control problem, and compared the result to the SSDI technique. Both theoretical and numerical results demonstrated better control performance of SSDNC, as compared to SSDI, for most non-optimal switching frequencies.

\subsubsection{Synchronized Switched Damping on Negative Ca- pacitance and Inductance (SSDNCI)}

Mokrani et al. [76] improved the damping performance, by combining the adaptive nature of SSDI, and enhanced performance of a negative capacitance, in a technique called synchronized switch damping on negative capacitance and inductance (SSDNCI) (see Fig. 4 (f)). Adding a negative capacitance cancels the capacitance of the piezoelectric transducer, thus improving damping. The negative capacitance in series and in parallel configuration with the piezoelectric transducer was studied, and equivalent system parameters were established, as highlighted in Table 5 .

The damping ratios for SSDI and SSDNCI were derived as,

SSDI: $\quad \zeta_{S S D I}=\frac{2}{\pi}\left(\frac{1+\alpha}{1-\alpha}\right) k^{2}$ 


$$
\text { SSDNCI: } \zeta_{S S D N C I}=\frac{2}{\pi}\left(\frac{1+\alpha}{1-\alpha}\right)\left(\frac{1}{1-\beta}\right) k^{2}
$$

where, $\alpha$ is the overshoot during the switching of electrical shunt circuit, which is related to the electrical damping $\zeta_{e}$, according to $\alpha=e^{-\zeta_{e} \pi / \sqrt{1-\zeta_{e}^{2}}}$ and $\beta=C_{n} / C^{s}$ for parallel configuration, and $\beta=C / C_{n}$ for series configuration. Equations 18 and 19 show that the performance of both the SSDI and SSDNCI has strong parametric dependence, i.e. the damping performance is predicted in terms of electrical damping of the shunt circuit, and the ratio between the synthesized negative capacitance, and the capacitance of the stand-alone piezoelectric transducer. The damping ratios of SSDI and SSDNCI were experimentally determined, as follows,

- $\zeta_{S S D I}=2.37 \%$
- $\zeta_{S S D N C I}=4.61 \%$

This demonstrated the enhanced damping performance for SSDNCI, as compared to SSDI technique, thus confirming the theoretical predictions. Han et al. [77] used an SSDNCI technique for the vibration suppression, by connecting a negative capacitance in parallel to the SSDI network. The negative capacitance works during both states of the switching process, by building up the voltage on the piezoelectric transducer while the switch is open, and increasing the voltage inversion while the switch is closed. Numerical analysis was performed on a single-degree-offreedom oscillator. The energy dissipation was derived as a function of the capacitance ratio $\delta$, i.e the ratio between negative capacitance and piezoelectric capacitance; and resulted in a damping that was $(1+\delta)^{-3 / 2}$ times the original SSDI damping. Measurement on a clamped cantilever beam

Table 5. Equivalent properties of the piezoelectric transducer connected to a parallel or series negative capacitance, in Mokrani et al. [76].

\begin{tabular}{cccc}
\hline Equivalent parameter & Original system & $\begin{array}{c}\text { Parallel NC } \\
\left(-C_{n}\right)\end{array}$ & $\begin{array}{c}\text { Series NC } \\
\left(-C_{n}\right)\end{array}$ \\
\hline$C^{*}$ & $C$ & $C-C_{n}$ & $\frac{C}{1-C / C_{n}}$ \\
$d_{33}^{*}$ & $d_{33}$ & $d_{33}$ & $\frac{d_{33}}{1-C / C_{n}}$ \\
$k^{* 2}$ & $k^{2}$ & $\frac{k^{2}}{1-C_{n} / C}$ & $\frac{k^{2}}{1-C^{s} / C_{n}}$ \\
OC Stiffness & $\frac{K_{a}}{1-k^{2}}$ & $\frac{K_{a}}{1-k^{* 2}}$ & $\frac{K_{a}}{1-k^{2}}$ \\
SC Stiffness & $K_{a}$ & $K_{a}$ & $\frac{1-C / C_{n}}{1-C^{s} / C_{n}}$ \\
Stability condition & - & $C_{n}<C^{s}$ & $C_{n}>C$ \\
\hline
\end{tabular}

$C:$ electrical capacitance of piezoelectric transducer when no forces are applied;

$C^{s}=C\left(1-k^{2}\right)$ is the blocked capacitance of the transducer;

$C_{n}:$ negative capacitance; $k$ : electromechanical coupling coefficient of transducer;

$K_{a}:$ stiffness of transducer in short circuit; $d_{33}$ : piezoelectric constant.

NC: negative capacitance; OC: open circuit; SC: short circuit.

Table 6. Summary of the control performance of SSDS, SSDI, SSDV, SSDVenh and SSDNC, in forced response.

\begin{tabular}{clc}
\hline Control Technique & Control Performance & Reference \\
\hline SSDS & $A_{p}=20 \lg \left(\frac{C \omega}{C \omega+\frac{4 \alpha^{2}}{\pi C_{p}}}\right)$ & Qiu et al. [78] \\
SSDI & $A_{p}=20 \lg \left(\frac{C \omega}{C \omega+\frac{4 \alpha^{2}}{\pi C_{p}} \frac{1+\gamma}{1-\gamma}}\right)$ & Qiu et al. [78] \\
SSDV & $A_{p}=20 \lg \left(\frac{C \omega}{C \omega+\frac{4 \alpha^{2}}{\pi C_{p}} \frac{1+\gamma}{1-\gamma}}\left(1-\frac{4 \alpha V_{s}}{\pi F} \frac{1+\gamma}{1-\gamma}\right)\right]$ & Qiu et al. [78] \\
SSDVenh & $A_{p}=20 \lg \left(\frac{C \omega}{C \omega+\frac{4 \alpha^{2}}{\pi C_{p}}(1+\beta) \frac{1+\gamma}{1-\gamma}}\right)$ & Qiu et al. [78] \\
SSDNC & $A_{p}=20 \lg \left(\frac{C \omega}{C \omega+\frac{4 \alpha^{2}}{\pi C_{p}} \frac{C n}{C_{n}-C_{p}}}\right)$ & Cheng et al. [74] \\
\hline
\end{tabular}


was used to validate the analytical results, which reported a $220 \%$ increase in energy dissipation, as compared to standard SSDI technique.

A summary of the control performance of SSDS, SSDI,

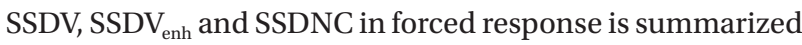
in Table 6, based on the performance index $A_{p}$ of amplitude attenuation, as defined in equation (14). Here, C is the damping coefficient of the mechanical system, $\omega$ denotes the frequency of vibration, $\alpha$ represents the force factor, $C_{p}$ is the capacitance of the piezoelectric element, $\gamma$ represents the voltage inversion coefficient, $V_{s}$ indicates the external voltage source, $\beta$ designates the voltage coefficient, and $C_{n}$ represents the negative capacitance of the shunt circuit.

\section{Conclusion and Future Direction}

A possible alternative that has emerged to both passive and active vibration control techniques is structural vibration control using piezoelectric based switched shunt circuit techniques. These semi-passive and semi-active control techniques benefit from the advantages of both active control i.e. high performance and adaptability, and passive control i.e. reliability and robustness, thus giving improved damping and control performance for broadband vibration excitation, under environmental variations. The main purpose of this article is to review control methods for the vibration suppression of piezostructural systems based upon the switched shunt circuit. First, the existing electromechanical modeling methods as used in the literature are reviewed, ranging from lumped parameter, to distributed parameter modeling, in mathematical and dynamic form. Then, a comprehensive literature review of vibration control laws using shunted piezostructural systems, ranging from passive to semi-passive, and semiactive control, was done, based on the classification of whether external power is supplied to the structures or not. In particular, recent articles investigating semi-passive and semi-active techniques based on SSD were given special attention. The aim of this article is to provide the required background material for researchers interested in the growing field of structural vibration damping and control, via piezoelectric based switched shunt circuit techniques. In this regard, a few points need to be mentioned for future directions, and practical application of these semi-passive and semi-active structural vibration control techniques.

Switch control laws for broadband vibration control: As discussed above, several switch control laws have been proposed for multimode vibration control; but these laws are limited to controlling few structural modes, with limited control performance. In an actual scenario, a structure is subjected to several vibration modes, due to varying environmental conditions and loads; therefore, more efficient switch control laws are needed to improve control performance, and provide higher robustness for broadband vibration.

Design of the low power shunt circuit: Usually, the power consumed by a switched shunt circuit is quite low, i.e. smaller than one milli-watt; but much higher power is consumed by the powerful digital signal processor (DSP), which is used to control the switch. As compared to active control techniques, much smaller power is consumed by semi-passive and semiactive control techniques; nevertheless, power consumption could be an important issue in many practical applications, especially in the aerospace field.

Self-powered switch control systems: A few researchers have attempted to develop self-powered switch control systems, e.g. Lallart et al. [84], Richard et al. [85], Niederberger \& Morari [86], and Delpero et al. [87]; but these systems used an analog switch control mechanism, which is not so efficient for broadband vibration control. Therefore, for efficient self-powered switch control systems, more sophisticated switch control laws are needed, in future. As complicated switch control laws consume more power, and more powerful DSP is required for their operation, a balance should be maintained between the energy consumption, and the control performance, of a self-powered switch control system.

\section{Acknowledgement}

The authors are grateful to the NUAA Fundamental Research Funds (No. NS2013010), and the National Science Foundation of China (No.50911140286), for grants and financial support.

\section{References}

[1] Hopkins, M.A., Henderson, D.A., Moses, R.W., Ryall, T., Zimcik, D.G., and Spangler, R.L., "Active vibrationsuppression systems applied to twin-tail buffering", Proc. SPIE Smart Structures and Materials: Industrial and Commercial Application of Smart Structures Technologies, Vol. 3326, issue, 1998, pp. 27-33. DOI:10.1117/12.310663.

[2] Simpson, J., and Schweiger, J., "Industrial approach to piezoelectric damping of large fighter aircraft components", Proc. SPIE Smart Structures and Materials: Industrial and Commercial Application of Smart Structures Technologies, 
Vol. 3326, issue, 1998, pp. 34-46. DOI:10.1117/12.310669.

[3] Kim, S., Han, C., and Yun, C., "Improvement of aeroelastic stability of hingeless helicopter rotor blade by passive piezoelectric damping", Proc. SPIE Smart Structures and Materials: Passive Damping and Isolation, Vol. 3672, issue, 1999, pp. 131-141. DOI:10.1117/12.349776.

[4] Wu, S., Turner, T.L., and Rizzi, S.A., "Piezoelectric shunt vibration damping of an F-15 panel under high-acoustic excitation", Proc. SPIE Smart Structures and Materials: Damping and Isolation, Vol. 3989, issue, 2000, pp. 276-287. DOI:10.1117/12.384568.

[5] Sheta, E.F., and Moses, R.W., "Active smart material control system for buffet alleviation", Journal of Sound and Vibration, Vol. 292, Issue 3-5, 2006, pp. 854-868. DOI: 10.1016/j.jsv.2005.09.002.

[6] Forward, R.L., "Electronic damping of vibrations in optical structures", Applied Optics, Vol.18, Issue 5, 1979, pp. 690-697. DOI: 10.1364/AO.18.000690.

[7] Hagood, N.W., Chung, W.H., and von Flotow, A., "Modelling of piezoelectric actuator dynamics for active structural control", Journal of Intelligent Material Systems and Structures, Vol. 1, Issue 3, 1990, pp. 327-354. DOI: 10.1177/1045389X9000100305.

[8] Hagood, N.W., and Crawley, E.F., "Experimental investigations of passive enhancement of damping space structures", Journal of Guidance, Control and Dynamics, Vol. 14, Issue 6, 1991, pp. 1100-1109. DOI: 10.2514/3.20763.

[9] Hagood, N.W., and von Flotow, A., "Damping of structural vibrations with piezoelectric materials and passive electrical networks", Journal of Sound and Vibration, Vol. 146, Issue 2, 1991, pp. 243-268. DOI: 10.1016/0022460X(91)90762-9.

[10] Hollkamp, J.J., "Multimodal passive vibration suppressionwith piezoelectric materialsandresonantshunts", Journal of Intelligent Material Systems and Structures, Vol. 5, Issue 1, 1994, pp. 49-56. DOI: 10.1177/1045389X9400500106.

[11] Law, H.H., Rossiter, P.L., Simon, G.P., and Koss, L.L., "Characterization of mechanical vibration damping by piezoelectric materials", Journal of Sound and Vibration, Vol. 197, Issue 4, 1996, pp. 489-513. DOI:10.1006/jsvi.1996.0544.

[12] Behrens, S., Moheimani, S.O.R., and Fleming, A.J., "Multiple mode current flowing passive piezoelectric shunt controller", Journal of Sound and Vibration, Vol. 266, Issue 5, 2003, pp. 929-942. DOI: 10.1016/S0022-460X(02)01380-9.

[13] Dong, X.J., Meng, G., and Peng, J.C., "Vibration control of piezoelectric smart structures based on system identification technique: Numerical simulation and experimental study", Journal of Sound and Vibration, Vol. 297, Issue 3-5, 2006, pp. 680-693. DOI: 10.1016/j.jsv.2006.04.021.

[14] Silva, S.D., Junior, V.L., and Brennan, M.J., “Design of a control system using linear matrix inequalities for the active vibration control of a plate", Journal of Intelligent Material Systems and Structures, Vol. 17, Issue 1, 2006, pp. 81-93. DOI:10.1177/1045389X06056341.

[15] Qiu, Z.C., Han, J.D., Zhang, X.M., Wang, Y.C., and $\mathrm{Wu}, \mathrm{Z} . \mathrm{W}$., "Active vibration control of a flexible beam using a non-collocated acceleration sensor and piezoelectric patch actuator", Journal of Sound and Vibration, Vol. 326, Issue 3-5, 2009, pp. 438-455. DOI: 10.1016/j.jsv.2009.05.034.

[16] Sunar, M., and Rao, S.S., "Recent advances in sensing and control of flexible structures via piezoelectric materials technology", Applied Mechanics Reviews, Vol. 52, Issue 1, 1999, pp. 1-16. DOI:10.1115/1.3098923.

[17] Tang, J., Liu, Y., and Wang, K.W., "Semiactive and active-passive hybrid structural damping treatments via piezoelectric materials", Shock and Vibration Digest, Vol. 32, Issue3,2000,pp.189-200.DOI:10.1177/058310240003200302.

[18] Benjeddou, A., "Advances in piezoelectric finite element modeling of adaptive structural elements: a survey", Computers \& Structures, Vol. 76, Issue 1-3, 2000, pp. 347-363. DOI: 10.1016/S0045-7949(99)00151-0.

[19] Benjeddou, A., "Advances in hybrid active-passive vibration and noise control via piezoelectric and viscoelastic constrained layer treatments", Journal of Vibration and Control, Vol. 7, Issue 4, 2001, pp. 565-602. DOI: 10.1177/107754630100700406.

[20] Trindade, M.A., and Benjeddou, A., "Hybrid active-passive damping treatments using viscoelastic and piezoelectric materials: Review and Assessment", Journal of Vibration and Control, Vol. 8, Issue 6, 2002, pp. 699-745. DOI: 10.1177/1077546029186.

[21] Moheimani, S.O.R., "A survey of recent innovations in vibration damping and control using shunted piezoelectric transducers", IEEE Transactions on Control Systems Technology, Vol. 11, Issue 4, 2003, pp. 482-494. DOI:10.1109/ TCST.2003.813371.

[22] Sodano, H.A., Inman, D.J., and Park, G., "A review of power harvesting from vibration using piezoelectric materials", The Shock and Vibration Digest, Vol. 36, Issue 3, 2004, pp. 197-205. DOI: 10.1177/0583102404043275.

[23] Anton, S.R., and Sodano, H.A., "A review of power harvesting using piezoelectric materials (2003-2006)", Smart Materials and Structures, Vol. 16, Issue 3, 2007, pp. R1-R21. DOI:10.1088/0964-1726/16/3/R01.

[24] Wang, Y., and Inman, D.J., "A survey of control strategies for simultaneous vibration suppression and energy harvesting via piezoceramics", Journal of Intelligent Material Systems and Structures, Vol. 23, Issue 18, 2012, pp. 2021-2037. DOI:10.1177/1045389X12444485.

[25] Song, G., Sethi, V., and Li, H-N., "Vibration control 
of civil structures using piezoceramic smart materials: A review", Journal of Engineering Structures, Vol. 28, Issue 11, 2006, pp. 1513-1524. DOI:10.1016/j.engstruct.2006.02.002.

[26] Fisco, N.R., and Adeli, H., "Smart structures: Part IActive and semi-active control”, Scientia Iranica Transactions A: Civil Engineering, Vol. 18, Issue 3, 2011, pp. 275-284. DOI:10.1016/j.scient.2011.05.034.

[27] Fisco, N.R., and Adeli, H., "Smart structures: Part II- Hybrid control systems and control strategies", Scientia Iranica Transactions A: Civil Engineering, Vol. 18, Issue 3, 2011: pp. 285-295. DOI: 10.1016/j.scient.2011.05.035.

[28] Corr, L.R., and Clark, W.W., "Comparison of lowfrequency piezoelectric switching shunt techniques for structural damping", Smart Structures and Materials, Vol. 11, Issue 3, 2002, pp. 370-376. DOI:10.1088/0964-1726/11/3/307.

[29] Davis, C.L., and Lesieutre, G.A., "An actively tuned solid-state vibration absorber using capacitive shunting of piezoelectric stiffness", Journal of Sound and Vibration, Vol. 232, Issue 3, 2000, pp. 601-617. DOI:10.1006/jsvi.1999.2755.

[30] Larson G.D., Rogers, P.H., and Munk, W., "State switched transducers: A new approach to high-power, lowfrequency, underwater projectors", Journal of Acoustical Society of America, Vol. 103, Issue 3, 1998, pp. 1428-1441. DOI:10.1121/1.421283.

[31] Badel, A., Lagache, M., and Guyomar, D., et al., "Finite element and simple lumped modeling for flexural nonlinear semi-passive damping", Journal of Intelligent Material Systems and Structures, Vol. 18, Issue 7, 2007: pp. 727-742. DOI: 10.1177/1045389X06069447.

[32] Cunefare, K.A., "State-switched absorber for vibration control of point-excited beams", Journal of Intelligent Material Systems and Structures, Vol. 13, Issue 2-3, 2002, pp. 97-105. DOI: 10.1177/104538902761402495.

[33] Niederberger, D., Fleming, A., Moheimani, S.O.R., and Morari, M., "Adaptive multi-mode resonant piezoelectric shunt damping", Smart Materials and Structures, Vol. 13, Issue 5, 2004, pp. 1025-1035. DOI:10.1088/0964-1726/13/5/007.

[34] Lallart, M., Harari, S., and Petit, L., et al., "Blind switch damping (BSD): A self-adaptive semi-active damping technique", Journal of Sound and Vibration, Vol. 328, No. 1-2, 2009, pp. 29-41. DOI:10.1016/j.jsv.2009.07.030.

[35] Guyomar, D., Richard, C., and Mohammadi, S., "Damping behavior of semi-passive vibration control using shunted piezoelectric materials", Journal of Intelligent Material Systems and Structures, Vol. 19, Issue 8, 2008, pp. 977-985. DOI: 10.1177/1045389X07083122.

[36] Ji, H., Qiu, J., Badel, A., and Zhu, K., "Semiactive vibration control of a composite beam using an adaptive SSDV approach", Journal of Intelligent Material Systems and Structures, Vol. 20, Issue 4, 2009, pp. 401-412.

\section{DOI:10.1177/1045389X08095182.}

[37] Ji, H., Qiu, J., Zhu, K., and Badel, A., "Two-mode vibration control of a beam using nonlinear synchronized switching damping based on the maximization of converted energy", Journal of Sound and Vibration, Vol. 329, Issue 14, 2010, pp. 2751-2767. DOI:10.1016/j.jsv.2010.01.012

[38] Erturk, A., and Inman, D.J., "Issues in mathematical modeling of piezoelectric energy harvesters", Smart Materials and Structures, Vol. 17, Issue 6, 2008, pp. 065016 (14pp). DOI:10.1088/0964-1726/17/6/065016.

[39] Guyomar, D., Lallart, M., and Monnier, T., "Stiffness tuning using a low-cost semiactive nonlinear technique", IEEE/ ASME Transactions on Mechatronics, Vol. 13, Issue 5, 2008, pp. 604-607. DOI: 10.1109/TMECH.2008.2004411.

[40] Guyomar, D., Richard, C., and Mohammadi, S., "Damping behavior of semi-passive vibration control using shunted piezoelectric materials", Journal of Intelligent Material Systems and Structures, Vol. 19, Issue 8, 2008, pp. 977-985. DOI: 10.1177/1045389X07083122.

[41] Caruso, G., "A critical analysis of electric shunt circuits employed in piezoelectric passive vibration damping", Smart Materials and Structures, Vol. 10, Issue 5, 2001, pp. 10591068. DOI:10.1088/0964-1726/10/5/322.

[42] Hollkamp, J.J., and Starchville, J.T.F., "A self-tuning piezoelectric vibration absorber", Journal of Intelligent Material Systems and Structures, Vol. 5, Issue 4, 1994, pp. 559-566. DOI:10.1177/1045389X9400500412.

[43] Konak, M.J., Powlesland, I.G., van der Velden, S.P., and Galea, S.P., "A self-powered discrete time piezoelectric vibration damper". Proc. SPIE Conf. Integrated Systems: SPIE, Vol. 3241, issue, 1997, pp. 270-279. DOI:10.1117/12.293506.

[44] Richard, C., Guyomar, D., Audigier, D., and Ching, G., "Semi-passive damping using continuous switching of a piezoelectric device", In Proc. SPIE Conf. Passive Damping Isolation, Newport Beach, CA, Vol. 3672, issue, 1999, pp. 104111. DOI:10.1117/12.349773.

[45] Tang, J., and Wang, K.W., "Active-passive hybrid piezoelectric networks for vibration control: Comparisons and improvement", Smart Materials and Structures, Vol. 10, No. 4, 2001, pp. 794-806. DOI:10.1088/0964-1726/10/4/325.

[46] Thorp, O., Ruzzene, M., and Baz, A., "Attenuation and localization of wave propagation in rods with periodic shunted piezoelectric patches". Smart Materials and Structures, Vol. 10, Issue 5, 2001, pp. 979-989. DOI:10.1088/0964-1726/10/5/314.

[47] Wu, S.Y., and Bicos, A.S., "Structural vibration damping experiments using improved piezoelectric shunts", In Proc. SPIE Conf. Passive Damping Isolation: SPIE, Vol. 3045, issue, 1997, pp. 40-50. DOI:10.1117/12.274217.

[48] Johnson, C.D., "Design of passive damping systems", 
Journal of Mechanical Design, Transactions of the ASME, Vol. 117, issue B, 1995, pp.171-176. DOI:10.1115/1.2836451.

[49] Wu, S.Y., "Piezoelectric shunts with a parallel R-L circuit for structural damping and vibration control", In Proc. SPIE Symp. Smart Structures Materials Passive Damping Isolation, May 1, Volume 2720, issue, 1996, pp. 259-269. DOI:10.1117/12.239093.

[50] dell'Isola, F., Maurini, C., and Porfiri, M., "Passive damping of beam vibrations through distributed electric networks and piezoelectric transducers: prototype design and experimental validation", Smart Materials and Structures, Vol. 13, Issue 2, 2004, pp. 299- 308. DOI:10.1088/09641726/13/2/008.

[51] Ramaratnam, A., and Jalili, N., "A switched stiffness approach for structural vibration control: Theory and realtime implementation", Journal of Sound \& Vibration, Vol. 291, No. 1-2, 2006, pp. 258-274. 10.1016/j.jsv.2005.06.012.

[52] Clark, W.W., "Semi-active vibration control with piezoelectric materials as variable stiffness actuators", Smart Structures and Materials 1999: Passive Dampingand Isolation, Vol. 3672, issue, 1999, pp. 123-130. DOI:10.1117/12.349775.

[53] Clark, W.W., "Vibration control with state-switched piezoelectric materials", Journal of Intelligent Material Systems and Structures, Vol. 11, Issue 4, 2000, pp. 263-271. DOI: 10.1106/18CE-77K4-DYMG-RKBB.

[54] Corr,L.R., andClark, W.W., "Energy dissipation analysis of piezoceramic semi-active vibration control", Journal of Intelligent Material Systems and Structures, Vol. 12, Issue 11, 2001, pp. 729-736. DOI: 10.1177/104538901400438028.

[55] Holdhusen, M.H., and Cunefare, K.A., "Damping effects on the state-switched absorber used for vibration suppression", Journal of Intelligent Material Systems and Structures, Vol.14, Issue 9, 2003, pp. 551-561. DOI: 10.1177/104538903036919.

[56] Corr, L.R., and Clark, W.W., "A novel semi-active multi-modal vibration control law for a piezoceramic actuator", Journal of Vibration and Acoustics, Vol. 125, Issue 2, 2003, pp. 214-222. DOI:10.1115/1.1547682.

[57] Richard, C., Guyomar, D., and Audigier, D., et al., "Enhanced semi-passive damping using continuous switching of a piezoelectric device on an inductor", In Proc. of SPIE Smart Structures and Materials 2000: Damping and Isolation, Vol. 3989, issue, 2000, pp. 288-299. DOI:10.1117/12.384569.

[58] Ducarne, J., Thomas, O., and Deu, J-F., "Structural vibration reduction by switch shunting of piezoelectric elements: modeling and optimization", Journal of Intelligent Material Systems and Structures, Vol. 21, Issue 8, 2010, pp. 797-816. DOI: 10.1177/1045389X10367835.

[59] Petit, L., Lefeuvre, E., Richard, C., and Guyomar, D., "A broadband semipassive piezoelectric techniquefor structural damping", Proceedings of SPIE International Symposium on Smart Structure Materials: Damping and Isolation, Vol. 5386, issue, 2004, pp. 414-425. DOI:10.1117/12.532716.

[60] Guyomar, D. and Badel, A., "Nonlinear semi-passive multimodal vibration damping: An efficient probabilistic approach", Journal of Sound and Vibration, Vol. 294, Issue 1-2, 2006, pp.249-268. DOI: 10.1016/j.jsv.2005.11.010.

[61] Lefeuvre, E., Badel, A., and Petit, L., et al., "Semipassive piezoelectric structural damping by synchronized switching on voltage sources", Journal of Intelligent Material Systems and Structures, Vol. 17, Issue 8-9, 2006, pp. 653-660. DOI: 10.1177/1045389X06055810.

[62] Badel, A., Sebald, G., and Guyomar, D., et al., "Piezoelectric vibration control by synchronized switching on adaptive voltage sources: towards wideband semi-active damping", Journal of the Acoustical Society of America, Vol. 119, No. 5, 2006, pp. 2815- 2825. DOI: 10.1121/1.2184149.

[63] Lallart, M., Badel, A., and Guyomar, D., "Nonlinear semi-active damping using constant or adaptive voltage sources: a stability analysis", Journal of Intelligent Material Systems and Structures, Vol. 19, Issue 10, 2008, pp. 1131-1142. DOI: 10.1177/1045389X07083612.

[64] Guyomar, D., Richard, C., and Mohammadi, S., "Semi-passive random vibration control based on statistics", Journal of Sound and Vibration, Vol. 307, Issue 3-5, 2007, pp. 818-833. DOI:10.1016/j.jsv.2007.07.008.

[65] Lallart, M., Lefeuvre, E., and Richard, C., et al., "Selfpowered circuit for broadband, multimodal piezoelectric vibration control", Sensors and Actuators A: Physical, Vol. 143, Issue 2, 2008, pp. 377-382. DOI: 10.1016/j.sna.2007.11.017.

[66] Neubauer, M., and Wallaschek, J., "Analytical and experimental investigation of the frequency ratio and switching law for piezoelectric switching techniques", Smart Materials and Structures, Vol.17, Issue 3, 2008, pp. 035003 (9pp). DOI:10.1088/0964-1726/17/3/035003.

[67] Harari, S., Richard, C., and Gaudiller, L., "New semiactive multi-modal vibration control using piezoceramic components", Journal of Intelligent Material Systems and Structures, Vol. 20, Issue 13 , 2009, pp. 1603-1613. DOI: 10.1177/1045389X09102561.

[68] Ji, H., Qiu, J., and Badel, A., et al., "Semi-active vibration control of a composite beam by adaptive synchronized switching on voltage sources based on LMS algorithm", Journal of Intelligent Material Systems and Structures, Vol. 20, Issue 8, 2009, pp. 939-947. DOI: 10.1177/1045389X08099967.

[69] Ji, H., Qiu, J., and Zhu, K., et al., "Multi-modal vibration control using a synchronized switch based on a displacement switching threshold", Smart Materials and Structures, Vol. 18, Issue 3, 2009, pp. 035016 (8 pp). DOI:10.1088/0964- 
1726/18/3/035016.

[70] Ji, H., Qiu, J., and Zhu, K.J., "Vibration control of a composite beam using self-sensing semi-active approach", Chinese Journal of Mechanical Engineering. Vol. 23, Issue *, 2010, pp. 663-670. DOI: 10.3901/CJME.2010.0.

[71] Ji, H., Qiu, J., and Xia, P., "Analysis of energy conversion in two-mode vibration control using synchronized switch damping approach", Journal of Sound and Vibration, Vol. 330, Issue 15, 2011, pp. 3539-3560. DOI: 10.1016/j.jsv.2011.03.004.

[72] Ji, H., Qiu, J., Xia, P., and Inman, D., "Analysis of energy conversion in switched-voltage control with arbitrary switching frequency", Sensors and Actuators A: Physical, Vol. 174, issue, 2012, pp. 162-172. DOI:10.1016/j.sna.2011.11.004.

[73] Ji, H., Qiu, J., Cheng, J., and Inman, D., "Application of a Negative Capacitance Circuit in Synchronized Switch Damping Techniques for Vibration Suppression", Journal of Vibration and Acoustics, Vol. 133, Issue 4, 2011, pp. 0410151-10. DOI:10.1115/1.4003146.

[74] Cheng, J., Ji, H., Qiu, J., and Takagi, T., "Semi-active vibration suppression by a novel synchronized switch circuit with negative capacitance", International Journal of Applied Electromagnetics and Mechanics, Vol. 37, Issue 4, 2011, pp. 291-308. DOI:10.3233/JAE-2011-1402.

[75] Ji, H., Qiu, J., Xia, P., and Nie, H., "Energy conversion and performance of switched-voltage control based on negative capacitance with arbitrary switching frequency". Smart Materials and Structures, Vol. 21, Issue 12, 2012, pp.125010 (11pp). DOI:10.1088/0964-1726/21/12/125010.

[76] Mokrani, B., Rodrigues, G., Ioan, B., Bastaits, R., and Preumont, A., "Synchronized switch damping on inductor and negative capacitance", Journal of Intelligent Material Systems and Structures, Vol. 23, No. 18, 2012, pp. 2065-2075. DOI:10.1177/1045389X11433493.

[77] Han, X., Neubauer, M., and Wallaschek, J., “Improved piezoelectric switch shunt damping technique using negative capacitance", Journal of Sound and Vibration, Vol. 332, Issue 1, 2013, pp. 7-16. DOI: 10.1016/j.jsv.2012.08.001.

[78] Qiu, J.H., Ji, H.L., and Shen, H., "Energy harvesting and vibration control using piezoelectric elements and a non-linear approach", In: 18th IEEE international symposium on the applications of ferroelectrics (ISAF), Piscataway, NJ, August, 2009, pp. 23-27. DOI:10.1109/ISAF.2009.5307559.
[79] Fleming, A.J., and Moheimani, S.O.R., "Adaptive piezoelectric shunt damping", Smart Materials and Structures, Vol. 12, Issue 1, 2003, pp.36-48. DOI:10.1088/09641726/12/1/305.

[80] Qiu, J., Ji, H., and Zhu, K., "Semi-active vibration control using piezoelectric actuators in smart structures", Frontiers of Mechanical Engineering in China, Vol. 4, Issue 3, 2009, pp. 242-251. DOI:10.1007/s11465-009-0068-z.

[81] Anderson, B.D.O., and Sumeth, V., Network Analysis and Synthesis: A Modern Systems Theory Approach, Englewood Cliffs, NJ, Prentice Hall, 1973.

[82] Edberg, D.L., and Bicos, A.S., "Design and development of passive damping concepts in advanced composite large space structures". In: 36th international SAMPE symposium and exhibition, San Diego, CA, 15-18 April, 1991.

[83] Richard, C., Guyomar, D., and Audigier, D., "An original damping approach using a switched piezoelectric device". In: Proceedings of the 10th international conference on adaptive structures and technologies (ICAST 1999), Paris, France, 11-13 October, 1999, Lancaster, PA, pp 21-28.

[84] Lallart, M., Lefeuvre, E., Richard, C., and Guyomar, D., "Self-powered circuit for broadband, multimodal piezoelectric vibration control", Sensors and Actuators A: Physical, Vol. 143, Issue 2, 2007, pp. 377-382. DOI: 10.1016/j. sna.2007.11.017.

[85] Richard, C., Guyomar, D., and Lefeuvre, E., "Selfpowered Electronic Breaker with Automatic Switching by Detecting Maxima or Minima of Potential Difference Between its Power Electrodes", Patent \# PCT/FR2005/003000, publication number: WO/2007/063194, 2007.

[86] Niederberger, D., and Morari, M., "An autonomous shunt circuit for vibration damping", Smart Materials and Structure, Vol. 15, Issue 2, 2006, pp. 359-364. DOI:10.1088/0964-1726/15/2/016.

[87] Delpero, T., Di Lillo, L., Bergamini, A.E., and Ermanni, P., "Energy harvesting module for the improvement of the damping performance of autonomous synchronized switching on inductance", Journal of Intelligent Material Systems and Structures, Vol. 24, Issue 7, 2012, 837-845.

DOI:10.1177/1045389X12463463. 